\title{
REVIEW
}

\section{Biology, ecology, and status of the smalltooth sawfish Pristis pectinata in the USA}

\author{
Adam B. Brame ${ }^{1, *}$, Tonya R. Wiley ${ }^{2}$, John K. Carlson ${ }^{3}$, Sonja V. Fordham ${ }^{4}$, \\ R. Dean Grubbs ${ }^{5}$, Jason Osborne ${ }^{6}$, Rachel M. Scharer ${ }^{7}$, Dana M. Bethea ${ }^{1}$, \\ Gregg R. Poulakis ${ }^{7}$
}

\author{
${ }^{1}$ NOAA Fisheries Service, Southeast Regional Office, St Petersburg, Florida 33701, USA \\ ${ }^{2}$ Havenworth Coastal Conservation, Palmetto, Florida 34221, USA \\ ${ }^{3}$ NOAA Fisheries Service, Southeast Fisheries Science Center, Panama City, Florida 32408, USA \\ ${ }^{4}$ Shark Advocates International, Washington, DC 20036, USA \\ ${ }^{5}$ Florida State University Coastal and Marine Laboratory, St. Teresa, Florida 32358, USA \\ ${ }^{6}$ National Park Service, South Florida Natural Resource Center, Homestead, Florida 33034, USA \\ ${ }^{7}$ Fish and Wildlife Research Institute, Florida Fish and Wildlife Conservation Commission, \\ Charlotte Harbor Field Laboratory, Port Charlotte, Florida 33954, USA
}

\begin{abstract}
The smalltooth sawfish Pristis pectinata is threatened with extinction throughout its range and has been designated as Critically Endangered by the IUCN. In the USA, the species historically ranged from Texas to North Carolina, but mortality in fisheries and habitat loss have reduced the range to primarily southwest Florida. The US population was listed as endangered under the US Endangered Species Act in 2003. At that time, data on the biology and ecology of the species were limited. Research and outreach efforts have since expanded, and the quality and quantity of information has increased such that the US population is now one of the most wellstudied sawfish populations worldwide. Smalltooth sawfish are born in litters of 7-14 individuals at lengths of $64-81 \mathrm{~cm}$ stretched total length (STL), reach maturity in 7-11 yr at approximately $340 \mathrm{~cm}$ STL for males and $370 \mathrm{~cm}$ STL for females, grow to a maximum size of about $500 \mathrm{~cm} \mathrm{STL}$, and live an estimated $30 \mathrm{yr}$ in the wild. Smalltooth sawfish are piscivorous and shift from shallow estuarine waters as small juveniles to a broader array of coastal habitats as large juveniles and adults. The species is physiologically resilient to anthropogenic stressors, but preserving habitat and reducing fishing effects remain priorities. Data synthesized in this review have advanced our understanding of smalltooth sawfish life history and habitat needs, as well as the threats that continue to affect the population. Cumulatively, these data support optimism for recovery of the smalltooth sawfish in the USA and potentially beyond, though recovery will still require decades.
\end{abstract}

KEY WORDS: Elasmobranch $\cdot$ Pristidae $\cdot$ Age and growth $\cdot$ Population recovery $\cdot$ Conservation · Habitat use $\cdot$ Management

\section{INTRODUCTION}

Of the chondrichthyans, sawfishes (Pristidae) are the most threatened with extinction (Dulvy et al. 2014 , 2016). Globally, 3 of the 5 sawfish species

\footnotetext{
${ }^{*}$ Corresponding author: adam.brame@noaa.gov
}

are listed as Critically Endangered on the International Union for Conservation of Nature Red List of Threatened Species (Carlson et al. 2013, Kyne et al. 2013, Simpfendorfer 2013). All 5 species have experienced declines in their spatial distributions

(C) T. R. Wiley, S. V. Fordham, R. D. Grubbs, R. M. Scharer, G. R. Poulakis and, outside the USA, the US Government 2019. Open Access under Creative Commons by Attribution Licence. Use, distribution and reproduction are unrestricted. Authors and original publication must be credited.

Publisher: Inter-Research · www.int-res.com 
due in large part to their coastal habitats where they interact with many fisheries (Seitz \& Poulakis 2006, Dulvy et al. 2016). The Critically Endangered smalltooth sawfish Pristis pectinata is endemic to the Atlantic Ocean and was historically found in the eastern Atlantic along the west coast of Africa from Angola to Mauritania and in the western Atlantic from the mid-Atlantic states of the USA to Uruguay, including the Gulf of Mexico. Smalltooth sawfish populations have significantly declined, and Dulvy et al. (2016) estimated that the species may be found in less than $20 \%$ of its former range worldwide.

The Ocean Conservancy (formerly the Center for Marine Conservation) petitioned the National Marine Fisheries Service (NMFS) in 1999 to list the North American population of smalltooth sawfish as endangered under the US Endangered Species Act of 1973 (ESA). The subsequent status review (NMFS 2000) determined that the US population was a distinct population, as defined by the ESA, which was in danger of extinction throughout its range; it was therefore listed as endangered under the ESA in 2003. At the time of the listing, little was known about the biology and ecology of the species. Since then, research and outreach efforts have increased substantially, and the quality and quantity of public, scientific, and commercially derived information on smalltooth sawfish has also increased such that this population is one of the most well-studied sawfish populations worldwide. The purpose of this review is to synthesize all available information on the US population of the smalltooth sawfish. This comprehensive summary outlines the current state of knowledge on this species and will serve as a resource to direct future conservation, management, and research actions.

\section{METHODS}

To complete this review, all available public, scientific, and commercial (bycatch data from federal fisheries) information on the species was collected and evaluated. This includes the recovery plan (NMFS 2009a), the juvenile critical habitat designation (NMFS 2009b, Norton et al. 2012), the ESA 5 yr review (NMFS 2010), peer-reviewed scientific papers, grant reports, and meeting presentations. Additional scientific information was solicited from the US Smalltooth Sawfish Recovery Implementation Team and all permitted researchers and their collaborators.

\section{RESULTS}

\subsection{Spatial distribution}

In the western Atlantic Ocean, the smalltooth sawfish was historically reported from Brazil through the greater Caribbean and Central America (including The Bahamas, Cuba, Honduras, and Belize), the Gulf of Mexico, and the US Atlantic coast (Carlson et al. 2013). However, the species is now found in less than $20 \%$ of its former range worldwide (Dulvy et al. 2016), and The Bahamas is currently the only known country other than the USA where smalltooth sawfish can be reliably encountered (Guttridge et al. 2015). Ongoing tagging and genetic research suggest that there is no mixing between populations in the USA and The Bahamas (Carlson et al. 2013, R. D. Grubbs unpubl. data).

Although US landings have been recorded from Texas to New York (NMFS 2000), those north of the Carolinas were likely vagrants. The true historical distribution likely ranged from Texas to about North Carolina. However, the majority of records have always occurred in peninsular Florida. Records north of Florida along the US east coast only occurred during spring and summer periods (May to August) when inshore waters are warmest. These historical encounters were adults and likely represented seasonal migrants, wanderers, or colonizers from the core Florida population(s) rather than members of a continuous, even-density population (Bigelow \& Schroeder 1953). Winter water temperatures and the lack of appropriate coastal habitat (e.g. shallow, euryhaline mangrove-lined shoreline) serve as major environmental constraints limiting the northern range of the smalltooth sawfish (Poulakis et al. 2011, Scharer et al. 2017, this Theme Section).

Public encounter research over the last 2 decades indicates that Florida remains the region with the largest numbers of smalltooth sawfish (Seitz \& Poulakis 2002, Poulakis \& Seitz 2004, Wiley \& Simpfendorfer 2010, Waters et al. 2014). Current records from the east coast of Florida remain scarce compared to the Gulf of Mexico coast, Florida Bay, and the Florida Keys. Most of the recent encounter records from the east coast of Florida have been of larger sawfish occurring along the beaches and at offshore reefs, but a few juvenile individuals have been recently reported inside the Indian River Lagoon estuarine system (Wiley \& Simpfendorfer 2010, G. R. Poulakis unpubl. data). The species is rarely observed within Biscayne National Park on Florida's southeast coast, and efforts by resource 
management and law enforcement personnel to complete weekly creel surveys of recreational fishers there have indicated that recreational fishers are neither catching smalltooth sawfish nor encountering them in the water (Lewis 2008). Since 2003, there have only been occasional reports from the US east coast north of Florida and in the Gulf of Mexico west of Florida (Wiley \& Simpfendorfer 2010, Waters et al. 2014).

Encounter data suggest that larger individuals migrate seasonally northward up the US east coast (NMFS 2009a), although early satellite tracking data were not able to confirm such behavior (Carlson et al. 2014). Papastamatiou et al. (2015) obtained some evidence to support the migration hypothesis, as northward summer movements were observed from 3 individuals, but no data were collected during late fall and winter to observe subsequent southerly movements. The recapture of an adult in 2015 off Cumberland Island, Georgia, which was originally tagged in 2010 in the Florida Keys (NMFS unpubl. data), and the recovery of a satellite tag in the Gulf of Mexico off Charlotte Harbor from a sawfish originally tagged in Florida Bay (R. D. Grubbs unpubl. data) provide some evidence of northward movements. More recently, multiple adults tagged in the Florida Keys and Florida Bay have been detected on acoustic receivers as far north as Cape Canaveral on the Atlantic coast, with 1 sawfish detected in Georgia waters, and as far north as Tampa Bay on the Gulf coast (R. D. Grubbs unpubl. data). Preliminary data have also shown southerly movements of large juveniles from Charlotte Harbor to the lower Florida Keys during late fall and winter (G. R. Poulakis \& R. M. Scharer unpubl. data). The recent initiation of the use of internally placed acoustic transmitters, which last up to a decade, will likely determine whether consistent migrations occur along both coasts of Florida.

\subsection{Habitat use}

In general, the smalltooth sawfish inhabits shallow $(<10 \mathrm{~m})$ coastal waters, estuaries, and rivers of the tropics and subtropics, to a maximum depth rarely exceeding $100 \mathrm{~m}$ (Carlson et al. 2014, Dulvy et al. 2016). Encounters with the species from both public and research sources have provided insight into habitat use across all life stages. Associations between encounter locations and shallow-water habitats such as mangrove shorelines have been documented, and encounters have most often been reported over mud or sand bottoms (Poulakis \& Seitz
2004, Wiley \& Simpfendorfer 2010). Public encounters, fisheries-independent sampling, and acoustic monitoring have identified river mouths as areas where all life stages have been observed, especially juveniles (Seitz \& Poulakis 2002, Poulakis et al. 2011, Norton et al. 2012). Major river mouths and similar habitats downstream of other sources of freshwater such as the Faka Union Canal and the Turner River have been identified as perennial nurseries in Florida (e.g. Simpfendorfer et al. 2010, Scharer et al. 2017 this Theme Section, Hollensead et al. 2018 this Theme Section).

This species displays ontogenetic changes in habitat use with smaller animals in shallower water and larger animals in deeper water (Poulakis \& Seitz 2004, Simpfendorfer et al. 2010, 2011, Wiley \& Simpfendorfer 2010, Poulakis et al. 2013). Juveniles $<220 \mathrm{~cm}$ have the most specific habitat associations in nearshore areas, which are targeted relatively easily with research and recovery efforts (e.g. juvenile critical habitat designation, fishery-independent gill net surveys in shallow water). Large juveniles and adults have more varied habitat associations, and future research and recovery efforts may need to be more broadly based or targeted at specific areas that may provide the greatest benefits to this portion of the population (e.g. aggregating, mating, feeding).

\subsubsection{Small juveniles}

Considering the abundance of young of the year (YOY, up to $\sim 150 \mathrm{~cm}$ stretched total length [STL]) and other small juveniles $(<220 \mathrm{~cm}$ STL) in specific areas, and following the nursery framework of Heupel et al. (2007), 5 nursery areas were identified in southwest Florida (Norton et al. 2012; our Fig. 1). These nurseries were geographically combined by NMFS to designate 2 juvenile critical habitat units under the ESA for the conservation of smalltooth sawfish (NMFS 2009b, Norton et al. 2012; our Fig. 1). Red mangroves and shallow, euryhaline waters were identified as specific habitat features essential for the conservation of the species, as these features provide high prey availability and habitat for predator avoidance.

Small juveniles show high fidelity to specific areas within the nurseries for several months and increase home range with growth (Simpfendorfer et al. 2010, 2011, Hollensead et al. 2016, Scharer et al. 2017). In general, small juveniles have small daily activity spaces of $0.1 \mathrm{~km}^{2}$ in backcountry portions of estuaries or $1.0 \mathrm{~km}$ of linear distance in rivers, and these 

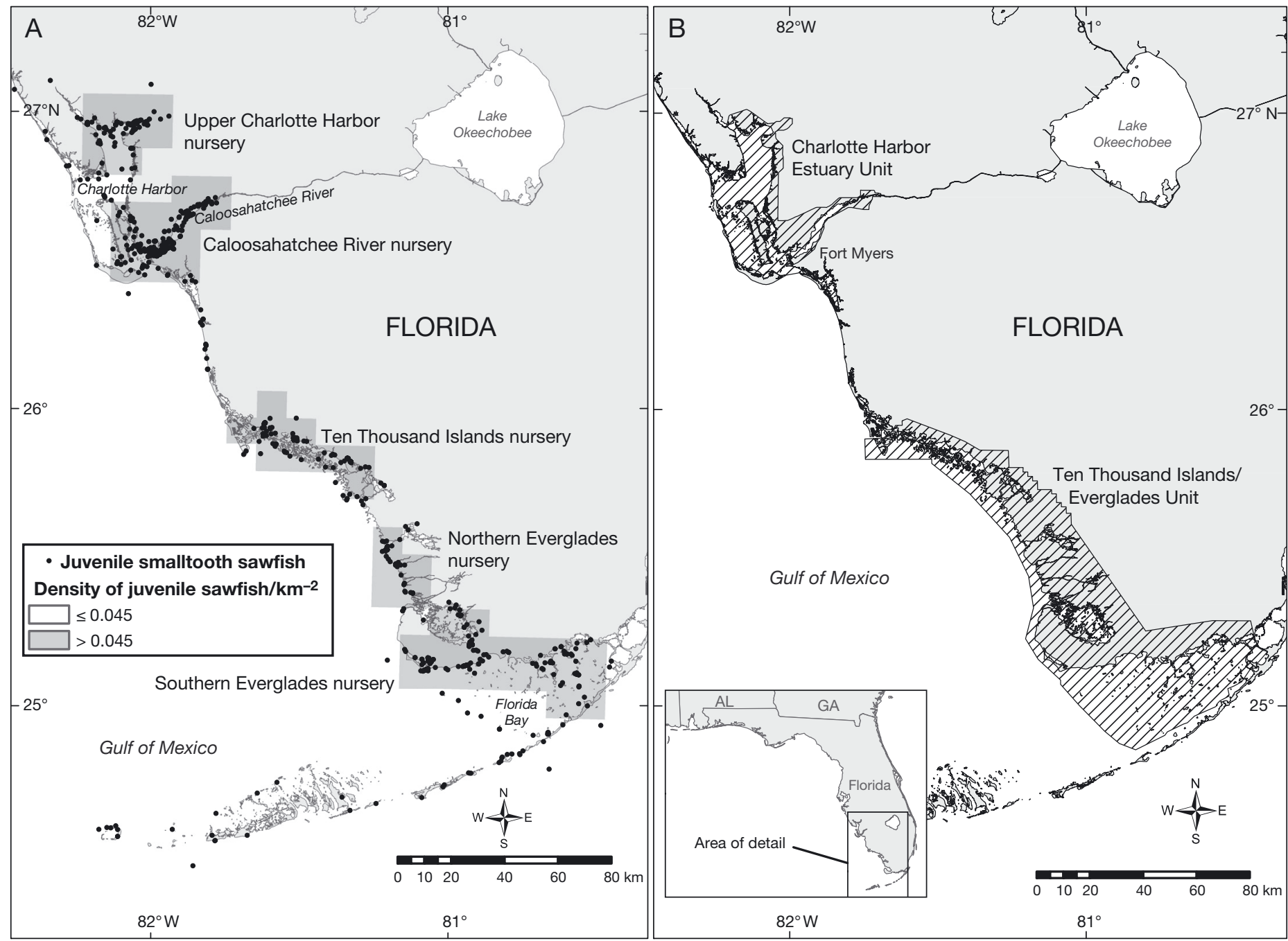

Fig. 1. (A) Five smalltooth sawfish nursery areas identified in southwest Florida, USA, and (B) 2 designated juvenile smalltooth sawfish critical habitat units, modified from Norton et al. (2012)

increase with size (Simpfendorfer et al. 2010, 2011, Hollensead et al. 2016, Scharer et al. 2017). Individuals $<100 \mathrm{~cm}$ STL had the smallest home ranges, low linearity of movement, a closer association with red mangrove shorelines, and a preference for the shallowest water. Trends also suggest that YOY sometimes have increased rates of movement or activity space depending on the nursery and time of day (Poulakis et al. 2016, Huston et al. 2017 this Theme Section, Hollensead et al. 2018). Juveniles used shallow areas near shore during the day and moved into deeper waters away from shore at night, although YOY remained closer to shore and made shorter excursions than individuals $\geq 150 \mathrm{~cm}$ STL (Huston et al. 2017). Recent data from acoustic telemetry suggest that juveniles $150-220 \mathrm{~cm}$ STL migrate over greater distances than previously assumed (A. Kroetz unpubl. data). Expansion in activity space with growth provides a mechanism for ontogenetic shifts in habitat use (Simpfendorfer et al. 2010, Poulakis et al. 2013).

Juveniles $<220 \mathrm{~cm}$ STL show relatively consistent patterns of habitat use among individuals of similar size and have strong associations with red mangrove shorelines and nearby shallow water (Simpfendorfer et al. 2010, Poulakis et al. 2011). For example, Huston et al. (2017) reported that juveniles were found near red mangroves 10 times more often than at seawalls. Similarly, sawfish using non-main-stem river habitats in Charlotte Harbor rivers spent more time in canals with mangroves than in canals without mangroves (Poulakis et al. 2013, Scharer et al. 2017). In the Ten Thousand Islands region, Hollensead et al. (2016) suggested selection for habitats close to mangrove 
shorelines, and in all cases, the mean distance of actively tracked animals from the mangrove-fringe was $<100 \mathrm{~m}$. Therefore, natural shorelines and areas with high mangrove prop root density are particularly important to preserve (Poulakis et al. 2013, Huston et al. 2017, Hollensead et al. 2018).

Within the identified nurseries (Fig. 1), multiple lines of evidence, including public encounter reports, fishery-independent catch rates, and acoustic monitoring, have shown disproportionately greater use of particular shorelines or embayments (Poulakis et al. 2011, 2013, 2016, Hollensead et al. 2016, 2018). Research on these higher-use areas (termed 'hotspots' by Poulakis et al. 2011) has shown that juveniles move within and between them depending on a variety of environmental factors such as food availability, water temperature, salinity, and weather events (Poulakis et al. 2013, 2016, Hollensead et al. 2016, 2018, Scharer et al. 2017). Ongoing research seeks to clarify the ecological role of these particular areas.

While the importance of shallow water and red mangrove-lined shorelines to juveniles has been well documented, there is growing evidence supporting some differences in habitat use between and within nurseries. Within the Caloosahatchee River nursery, juvenile sawfish distribution was significantly related to salinity; animals moved up the river in the dry season and down the river in the wet season to remain within their optimal salinity range of 18-30 (Poulakis et al. 2011, Simpfendorfer et al. 2011). Scharer et al. (2017) also found that juveniles moved seasonally throughout the Caloosahatchee River, yet juveniles in the nearby upper Charlotte Harbor nursery remained associated with a single high-use area despite the same regional climatic conditions. The difference in habitat use between the 2 nurseries was attributed to the geomorphology and freshwater inflow regimes of the rivers. Results suggest that care should be taken not to overgeneralize habitat use patterns between individual nurseries.

\subsubsection{Large juveniles and adults}

Two decades of encounter data show that large juveniles ( $>220 \mathrm{~cm}$ STL) and adults occur from shallow coastal waters to deeper shelf waters depending on the time of year (Seitz \& Poulakis 2002, Poulakis \& Seitz 2004, Wiley \& Simpfendorfer 2010, Waters et al. 2014). In general, adults have been observed in deep (up to $122 \mathrm{~m}$ ) waters off the Florida Keys in winter and in the shallow waters of Florida Bay during the rest of the year (Poulakis \& Seitz 2004, Wiley \&
Simpfendorfer 2010). Carlson et al. (2014) reported that satellite-tagged adults generally remained in coastal waters within the region where they were initially tagged, traveling an average of $80 \mathrm{~km}$ from tag deployment to pop-up location. Seasonal movement rates of females differed significantly from those of males, with the greatest movements in autumn and winter. Tagged adults spent the majority of their time at shallow depths $(<10 \mathrm{~m})$ and warm water temperatures $\left(22-28^{\circ} \mathrm{C}\right)$. In a similar study, Papastamatiou et al. (2015) reported that adults rarely occurred in waters warmer than $30^{\circ} \mathrm{C}$, although they have occasionally been documented in water $32-34^{\circ} \mathrm{C}$ (Carlson et al. 2014). These data suggest that temperature is a cue for triggering seasonal movements of large juveniles and adults.

Limited data are available about site fidelity of large juveniles and adults (but see Section 3.5). Males displayed site fidelity to Florida Bay, as some individuals were recaptured 1-2 yr after originally being tagged, and showed high periods of residency at East Cape Canal with some individuals being detected almost daily over periods of 1-3 mo (Papastamatiou et al. 2015). Seitz \& Poulakis (2002) reported that 1 adultsized animal with a broken rostrum was recaptured multiple times in the same location during a month near Big Carlos Pass. Likewise, individuals without rostra have been recaptured multiple times over similar time periods near fishing piers (G. R. Poulakis unpubl. data). These observations suggest that individuals without rostra and those with damaged rostra may alter their normal behavior and exhibit site fidelity near popular fishing locations, perhaps because of the consistent food source provided by anglers.

Seasonal sexual segregation of adults has been reported, with males found in mangrove-lined canals in Florida Bay in the spring and females predominantly found in outer parts of the bay (Papastamatiou et al. 2015). Males left canals starting in late May, potentially as temperatures exceeded $30^{\circ} \mathrm{C}$. Some males and females migrated north (but still in south Florida) during the summer, while others may have remained within deeper portions of Florida Bay. Papastamatiou et al. (2015) found evidence of tidally related movements, with individuals swimming over warm shallow seagrass beds during the ebbing or flooding tide and residing in deeper, cooler channels at slack tide.

Although advances have been made regarding habitat use by larger individuals, data gaps remain for this size class. Public encounter data have revealed clusters of sightings of larger sawfish in areas such as southern Charlotte Harbor and off Collier, Monroe, and Martin Counties, Florida (Wa- 
ters et al. 2014), which should be studied to determine seasonality, residence time, and links to other portions of the range. Recent initiation of the use of internally placed acoustic transmitters, which last up to a decade, should increase our understanding of the habitat use and ecology of these larger individuals.

\subsection{Life history}

\subsubsection{Age and growth}

The smalltooth sawfish grows rapidly, especially while immature, and matures earlier than previously thought (Simpfendorfer et al. 2008, Scharer et al. 2012, Carlson \& Simpfendorfer 2015). Using tagrecapture data, Simpfendorfer et al. (2008) documented rapid growth for the first $2 \mathrm{yr}$ after birth, as juveniles doubled in length in the first year and exceeded $200 \mathrm{~cm}$ STL in their second year. Further research using length-frequency data and band counts on vertebrae also suggests rapid growth during early years (Simpfendorfer et al. 2008, Scharer et al. 2012).

Age and growth parameters based on the von Bertalanffy growth model were estimated using lengthfrequency data and band counts on vertebrae. Using lengths of captured individuals, Simpfendorfer et al. (2008) reported von Bertalanffy growth parameters of $600 \mathrm{~cm}$ STL for $L_{\infty}$ (theoretical maximum size), $0.14 \mathrm{yr}^{-1}$ for $k$ (growth coefficient), and $-0.863 \mathrm{yr}$ for $t_{0}$ (time at 0 length). Scharer et al. (2012) estimated $L_{\infty}=$ $448 \mathrm{~cm} \mathrm{STL}, k=0.219 \mathrm{yr}^{-1}$, and $t_{0}=-0.811 \mathrm{yr}$ using vertebrae. Differences in the results are likely related to the methods used. Simpfendorfer et al. (2008) relied primarily on length-frequency data from smaller individuals, while Scharer et al. (2012) used vertebral band counts from a larger size range.

Little information is available on maximum age and size. Using data from Scharer et al. (2012), Carlson \&
Simpfendorfer (2015) extrapolated a maximum age in the wild of about $30 \mathrm{yr}$. A juvenile caught and tagged in 2002 was recaptured as an adult in 2016 (R. D. Grubbs unpubl. data), lending support to the modeled age and growth parameters for sawfish in the wild. The oldest known captive smalltooth sawfish was a male held in the USA from 1 June 1968 until its death on 8 January 2012 (43 yr, $7 \mathrm{mo}, 7 \mathrm{~d}$ ), and the oldest smalltooth sawfish currently in captivity is a male at Sea World Orlando held since November 1989 (White \& Henningsen 2017). Maximum reported length has ranged from $540 \mathrm{~cm}$ STL (Bigelow \& Schroeder 1953) to $760 \mathrm{~cm}$ STL (Simpfendorfer 2005); however, to date, all smalltooth sawfish captured in US fisheryindependent research surveys have been less than $500 \mathrm{~cm}$ STL (R. D. Grubbs, J. K. Carlson \& G. R. Poulakis unpubl. data; Table 1). Therefore, maximum STL in the wild is likely about $500 \mathrm{~cm}$ (note that some sources used TL; however, we believe this to be generally analogous with STL as currenty used).

\subsubsection{Reproduction}

The smalltooth sawfish is yolk-sac viviparous; live young are born in estuarine waters (NMFS 2000). Captures of neonates with embryonic rostral sheaths indicate size at birth to be 64-81 cm STL (Poulakis et al. 2011, Bethea et al. 2012). While Bigelow \& Schroeder (1953) reported that gravid females carried 15-20 embryos, more recent information reports litter size to be 7-14 (Feldheim et al. 2017 this Theme Section, J. Gelsleichter unpubl. data). The gestation period is about $1 \mathrm{yr}$, and individual females have a biennial reproductive cycle (Feldheim et al. 2017). In Charlotte Harbor, parturition occurs from November to July, peaking between April and May (Poulakis et al. 2011). Farther south in the Ten Thousand Islands and Everglades National Park, parturition occurs in all months except September, peaking between March and July (J. K. Carlson unpubl. data).

Table 1. Life history characteristics for smalltooth sawfish Pristis pectinata in the USA. STL: stretched total length

\begin{tabular}{|lcl|}
\hline Variable & Value & Reference \\
\hline Litter size (n) & $7-14$ & Feldheim et al. (2017), J. Gelsleichter \& G. R. Poulakis unpubl. data \\
STL at birth $(\mathrm{cm})$ & $64-81$ & Poulakis et al. (2011), J. K. Carlson unpubl. data \\
Male STL at maturity $(\mathrm{cm})$ & 340 & J. Gelsleichter unpubl. data \\
Female STL at maturity $(\mathrm{cm})$ & 370 & J. Gelsleichter unpubl. data \\
Maximum known STL $(\mathrm{cm})$ & 455 & R. D. Grubbs unpubl. data \\
Estimated maximum STL $(\mathrm{cm})$ & 500 & R. D. Grubbs unpubl. data \\
Age at maturity $(\mathrm{yr})$ & $7-11$ & Carlson \& Simpfendorfer $(2015)$ \\
Estimated maximum age $(\mathrm{yr})$ & 30 & Carlson \& Simpfendorfer $(2015)$ \\
\hline
\end{tabular}


Due to a limited number of necropsied adults, there is still uncertainty in age and size at maturity, especially for females. Early estimates suggested maturity for males between 253 and $381 \mathrm{~cm}$ STL and about $360 \mathrm{~cm}$ STL for females (Simpfendorfer 2002, Simpfendorfer et al. 2008). However, J. Gelsleichter (unpubl. data) recently estimated male maturation at $340 \mathrm{~cm}$ STL based on clasper length and female maturation at $>350 \mathrm{~cm}$, and likely around $370 \mathrm{~cm}$ STL, based on estradiol levels. Backtransforming known lengths of maturity to age from the growth model of Scharer et al. (2012), Carlson \& Simpfendorfer (2015) predicted age at maturity of 7-11 yr for both sexes.

Field observations of adults with fresh mating wounds have occurred in the spring and early summer (R. D. Grubbs \& G. R. Poulakis unpubl. data). Papastamatiou et al. (2015) hypothesized that mating occurs in Florida Bay based on observations of aggregations of mature animals coinciding with the mating period, initial sexual segregation of adults followed by some evidence of females moving through areas where males showed seasonal residency, and a high percentage of animals exhibiting evidence of rostruminflicted injuries. Simultaneous captures of male and female sawfish, both with mating wounds, within the backcountry waters of Everglades National Park and the lower Florida Keys indicate that these vast shallow areas may also provide mating grounds for the species (R. D. Grubbs unpubl. data). Feldheim et al. (2017) suggested discrete mating aggregation sites in some parts of the range where parents interact over multiple years, based on genetic findings of full siblings born over 6 yr apart in Charlotte Harbor.

Recent studies have presented 2 unexpected results. First, Fields et al. (2015) documented the first examples of viable, wild parthenogens (asexually produced offspring) in any vertebrate while studying the smalltooth sawfish. Whether asexual reproduction is a response to the low population size or occurs occasionally in wild populations of other elasmobranchs is unknown. Because the parthenogens were immature and thus their reproductive competence is unknown, researchers are unsure if and how these individuals will contribute to the population. Second, to date, 5 functional male smalltooth sawfish, including immature and mature individuals, have been necropsied and all contained ovotestes, suggesting that a rudimentary form of hermaphroditism is normal in males (J. Gelsleichter \& G. R. Poulakis unpubl. data). Additional analyses of these and other aspects of reproduction in this species are forthcoming (J. Gelsleichter pers. comm.).

\subsection{Diet}

Using stable isotope ratios of carbon $\left(\delta^{13} \mathrm{C}\right)$ and nitrogen $\left(\delta^{15} \mathrm{~N}\right)$ from fin clips and opportunistically collected fecal samples, and comparing to known isotopic ratios of potential prey categories and sympatric species with known feeding habits, Poulakis et al. (2017, this Theme Section) found that smalltooth sawfish fed primarily on teleost and elasmobranch fishes at all life stages. Direct observations from field sampling, anglers, and necropsies have more specifically indicated that smalltooth sawfish feed on schooling baitfishes such as clupeids, carangids, mugilids, elopids, sparids, belonids, and elasmobranchs such as dasyatids (Poulakis et al. 2013, 2017, J. K. Carlson \& R. D. Grubbs unpubl. data).

\subsection{Relative abundance, genetic population health, and demographics}

There is no current estimate of the size of the US smalltooth sawfish population, though based on range contraction it is expected to be a fraction of its historical size. Contemporary datasets suggest that the current population is at least stable throughout its core range (Carlson et al. 2007, Carlson \& Osborne 2012), in southwest Florida from Charlotte Harbor to Florida Bay. Currently, 3 fisheries-independent surveys monitor the recovery of smalltooth sawfish in the USA. Using these data plus any new survey data to estimate relative abundance trends will be a high priority in the future.

Early on, the smalltooth sawfish was considered to have low productivity and limited ability to rebound from exploitation based on a life table model (Simpfendorfer 2000), but the demographic estimates were based largely on anecdotal information and life history data from another sawfish species. Using more recent life history information specific to smalltooth sawfish, Carlson \& Simpfendorfer (2015) estimated that population growth $(\lambda)$ was $1.237 \mathrm{yr}^{-1}$ if age at maturity was $7 \mathrm{yr}$ and decreased to $1.150 \mathrm{yr}^{-1}$ if age at maturity was 11 yr. Population viability scenarios exploring various anthropogenic effects suggested a high level of variability, but in the absence of fishing mortality or catastrophic climate effects, the population grew at a relatively rapid rate, approaching carrying capacity in 40 or 50 yr when the initial population was set at 2250 or 600 females, respectively. In another analysis, the effective number of breeding females in the Caloosahatchee River nursery was estimated between 28 and 78 individuals per bien- 
nial period with upper confidence intervals of $<200$ individuals (D. D. Chapman unpubl. data). If this estimate of breeding females is correct (28-78 females) and similar numbers of breeding females are found in each of the other 4 known nurseries (thus the total initial population would be 140-390 females), then Carlson \& Simpfendorfer's (2015) starting populations may be optimistic and the time estimates for recovery may be underestimated.

Given the magnitude of decline observed (as inferred from range contraction), initially there was some concern about the genetic health of the smalltooth sawfish population in Florida. However, Chapman et al. (2011) found that robust genetic variation persists in the US population. They found no evidence of a genetic bottleneck arising from the large population decline, there was a lack of inbreeding, and the population was genetically connected, indicating that the species should be managed as a single interbreeding unit.

Feldheim et al. (2017) reconstructed parental genotypes using samples taken from young, and these data showed how adult females are genetically tied to specific nursery areas, much like other species such as sea turtles and salmon. The study indicated high parturition site fidelity for specific nurseries within the Charlotte Harbor estuarine system. Thirtyfour females only gave birth in the Caloosahatchee River, 19 only gave birth in the Peace River, and 2 females used both nurseries. At first glance, these results conflict with the findings of Chapman et al. (2011) which indicate that the Florida breeding population is a singular unit. However, Feldheim et al. (2017) hypothesized that males are responsible for the genetic connectivity among nurseries, as males likely mate with females from multiple nurseries. Regardless, individual nurseries may need to be managed separately to account for the number or needs of reproductively active females. Future genetic analysis of smalltooth sawfish captured in Everglades National Park and the Ten Thousand Islands National Wildlife Refuge is necessary to clarify the role of males and determine whether females exhibit parturition site fidelity to nurseries there.

\subsection{Threats}

In reviewing the status of the smalltooth sawfish, NMFS reviewed a wide range of potential threats to the species. These included commercial trade in both live sawfish and parts (M. T. McDavitt unpubl. data), disease, predation, parasites (Bakenhaster et al. 2018 this Theme Section), habitat loss, fisheries, entanglement in marine debris (Seitz \& Poulakis 2006), use in aquaria, and a variety of stochastic events. While several of these threats adversely affected the population historically, bycatch in fisheries, habitat loss (including loss as a result of climate change), and natural stochastic events are the primary threats continuing to adversely affect the US population. Other threats have largely been reduced as a result of national and international regulations.

\subsubsection{Commercial and recreational fisheries}

Mortality in both commercial and recreational fisheries has been, and still is, the primary threat responsible for the decline in smalltooth sawfish abundance (NMFS 2009a, Poulakis \& Grubbs 2019 this Theme Section). While the species is required to be released, fishery interactions continue to result in both injury and mortality. The US Federal shrimp trawl fishery has reported the capture of 13 individuals from 2009 to 2018 (NMFS unpubl. data), although this number likely represents a small portion of actual captures given the low observer coverage of this fishery. Extrapolated total take estimates for the shrimp trawl fishery for the period 2008-2010 indicate that a total of 17-163 smalltooth sawfish were captured per year (Carlson \& Scott-Denton 2011). The shrimp trawl fishery is of particular concern, as interactions with this fishery generally result in the mortality of large and likely mature sawfish, thus reducing reproductive potential within the population. In contrast, since 2005, the US shark bottom longline fishery has captured 40 sawfish, with only 1 known mortality (J. K. Carlson unpubl. data). Based on the live release of large sawfish from longline gear, it is expected that sawfish are more resilient to capture on this gear in comparison to trawls and gill nets (Prohaska et al. 2018, Poulakis \& Grubbs 2019, both this Theme Section). Further, lactate and $\mathrm{HCO}_{3}$ blood levels of animals captured on longlines during permitted field activities indicate that the smalltooth sawfish is a relatively low stress species compared to other elasmobranchs (Prohaska et al. 2018).

Smalltooth sawfish were historically, and continue to be, captured in the recreational fishery (NMFS 2009a). Although, historically, sawfish were often retained, sometimes solely for the rostrum, federal regulations now prohibit retention. Therefore, while interactions within the recreational fishery are numerous, the level of mortality is likely low when sawfish are handled and released properly. While 
longer fights on hook-and-line gear as opposed to bottom longlines may elevate lactate and $\mathrm{HCO}_{3}$ levels, this species appears resilient and, when considered in conjunction with information from ongoing tagging and telemetry studies, post-release survival is expected to be high. However, researchers continue to receive reports of sawfish being retained or being released after the removal of their rostra.

\subsubsection{Habitat loss}

The only known nursery areas for the US population of smalltooth sawfish are located in southwest Florida (Fig. 1). Although much of this geographic area is federally protected as Everglades National Park and Ten Thousand Islands National Wildlife Refuge, historical freshwater delivery to these areas has been drastically modified as a result of upstream development. The modified hydrology continues to affect south and southwest Florida, but the specific effects on sawfish are unknown. The northern 2 nurseries are located in Charlotte Harbor, an urbanized estuary that remains vulnerable to further development, where mangrovelined shorelines have been replaced by waterfront residences and seawalls (Wiley \& Simpfendorfer 2010, Poulakis et al. 2011, 2013, 2016, Norton et al. 2012, Huston et al. 2017, Scharer et al. 2017). Prohaska et al. (2018) showed that juvenile smalltooth sawfish within the Charlotte Harbor estuary have higher metabolic stress compared to sawfish from more pristine nurseries, suggesting chronic stress may be associated with living in compromised habitats. While we are unsure of how chronic stress affects body condition, behavior, or survival, juvenile sawfish appear resilient and continue to be found in that estuary. Removal of red mangroves and shallow waters, features upon which juveniles rely for predator avoidance, are the most obvious habitat threats. Removal of these habitat features likely increases the threat of predation from known sawfish predators, including crocodiles (Thorburn et al. 2004), sharks (Compagno 1984, Thorburn et al. 2004; Fig. 2), and marine mammals such as dolphins (Bigelow \& Schroeder 1953).

\subsubsection{Other threats}

The effects of stochastic events (e.g. extreme cold weather events, hurricanes, and algal blooms) on smalltooth sawfish are largely unknown; however, these events have the potential to impede recovery. To date, cold temperatures have had the most sub- stantial known direct effects, such as mortalities and disruptions in habitat use. In January 2010, water temperatures throughout Florida decreased substantially following the passage of multiple cold fronts, and at least 15 juveniles and 1 adult were found dead during this period (Poulakis et al. 2011, Scharer et al. 2017). Following this weather event, directed research in the Ten Thousand Islands nursery yielded only 6 juvenile captures over the entire year, far fewer than typically captured during prior years with similar effort (Bethea et al. 2011a). That same research survey collected 42 smalltooth sawfish in 2011, suggesting the population was able to withstand the extreme cold episode (Bethea et al. 2011b). This cold event established the lower lethal temperature of $8-12^{\circ} \mathrm{C}$ for the smalltooth sawfish, depending on water depth and exposure time, which is similar to other cold-sensitive fishes that live at the northern extent of their range in Florida (Poulakis et al. 2011, Scharer et al. 2017). A less severe cold event occurred in 2011 that produced no known mortalities, but did influence habitat use. Normally, movements of juveniles in the Caloosahatchee River are well correlated with freshwater inflow effects such as salinity - they move upriver during the winter (Poulakis et al. 2013). However, juveniles moved downriver during these cold winters to seek less variable, warmer waters found in deeper habitats closer to the Gulf of Mexico (Boucek et al. 2017, Scharer et. al. 2017). Aperiodic cold events will be important to monitor if northern range expansion begins occurring during recovery, as they may limit successful long-term establishment in new areas.

Hurricanes are relatively common throughout the US range of the smalltooth sawfish. Since research be-

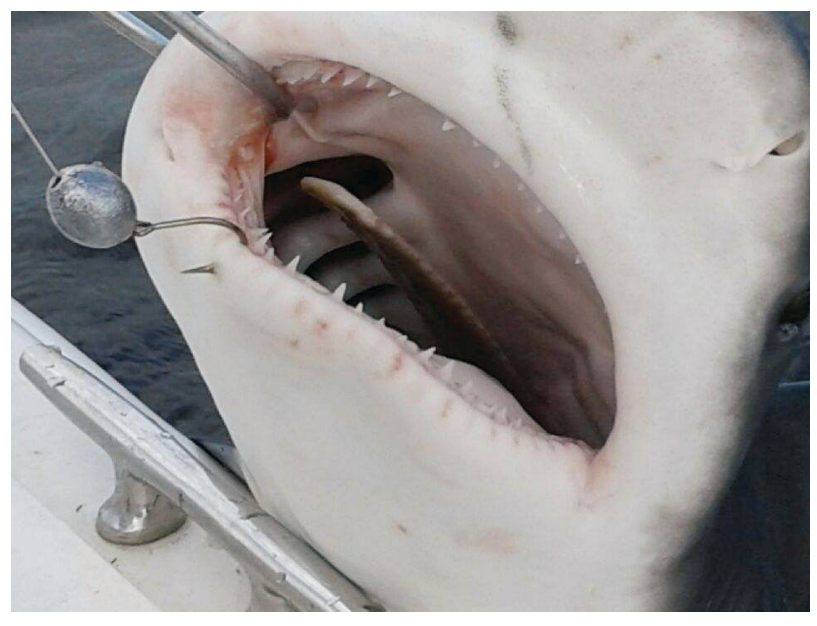

Fig. 2. Smalltooth sawfish Pristis pectinata in the mouth of a bull shark Carcharhinus leucas in Everglades National Park, Florida, USA. Photo by Rocco Madriz 
gan in the USA in the early 2000s, 2 major hurricanes have made landfall in Florida in the core range of the species: Hurricane Charley in 2004 and Hurricane Irma in 2017. Hurricane Charley, a compact storm, entered Charlotte Harbor from the Gulf of Mexico at category 4 strength and followed the estuary as it moved north into the Peace River-a known sawfish nursery. The short-term effects of the storm on the estuary were substantial and included hypoxic conditions and denuding of much of the red mangrove shoreline (Stevens et al. 2006); however, no mortalities were observed and the nursery is still functioning today (Scharer et al. 2017). While Hurricane Charley mostly affected the Charlotte Harbor estuary, Hurricane Irma affected the entire core range of the species, from the Florida Keys to Charlotte Harbor. Hurricane Irma made its first landfall in the lower Florida Keys at category 4 strength, made another landfall later the same day at Marco Island just north of the Ten Thousand Islands at category 3 strength, then proceeded north on land just to the east of Charlotte Harbor. Acoustically tagged juveniles from Florida Bay to Charlotte Harbor moved away from their normal shallow nurseries as the storm was passing, but in most cases returned within days of the passage of the storm (G. R. Poulakis \& J. K. Carlson unpubl. data).

Major red tide (Karenia brevis) blooms have occurred within the core range since at least the mid1800 s, and the smalltooth sawfish appears to have adapted to their occurrence. Blooms often begin in the Gulf of Mexico and, if large enough, can be carried into the high-salinity portions of the estuaries by flooding tides; however, the riverine sawfish nurseries are often buffered from the effects of these events because blooms cannot survive in salinity below about 24 (Vargo 2009). Perennial nutrient loading from human activities may increase the intensity and duration of these red tides ( $\mathrm{Hu}$ et al. 2006, Brand \& Compton 2007, Anderson et al. 2008). Water diversions and discharges associated with Lake Okeechobee have resulted in periodic bluegreen algae blooms in addition to the red tide events; however, it is unknown how these different blooms interact. Although major bloom events are often accompanied by reduced dissolved oxygen levels and extensive fish kills, so far, sawfish mortalities have not been reported during the bloom events.

\subsubsection{Climate change}

The Intergovernmental Panel on Climate Change (IPCC) has stated that global climate change is 'unequivocal' and its impacts on coastal resources may be significant (IPCC 2007, 2013). Some of the anticipated outcomes are (1) sea level rise, (2) increased frequency of severe weather events, (3) changes in air and water temperature, and (4) ocean acidification.

Sawfish are assumed to be at risk from climate change due to low intrinsic rates of population growth and slow rates of evolution (Field et al. 2009, Chin et al. 2010), although specific effects are hard to predict. Effects on sawfish habitat are clearer. Red mangroves and shallow $(<1 \mathrm{~m})$, euryhaline waters identified as habitat features essential for the conservation of smalltooth sawfish are likely to be affected by climate change, most notably through sea level rise, which increased by $0.19 \mathrm{~m}$ between 1901 and 2010 and is expected to increase 0.45 to $0.75 \mathrm{~m}$ by 2100 (IPCC 2013). Sea level increases would reduce the amount of shallow water available for juvenile smalltooth sawfish in areas where shorelines are armored (e.g. seawalls). Similarly, mangroves will be forced landward to remain at a preferred water inundation level and sediment surface elevation necessary for successful growth (Field 1995). Forced landward progression poses the greatest threat to mangroves in areas where there is limited or no room for landward or lateral migration due to shoreline armoring and coastal development (Semeniuk 1994). Reductions in the availability of shallow water or mangroves could have numerous ecological effects on sawfish, including increased sawfish predation, higher metabolic stress, and decreased body condition.

Changes to air and water temperatures may affect both the species and the habitats it relies upon. Given that sawfish distribution is limited to areas with water temperatures above $8-12^{\circ} \mathrm{C}$, warming could result in a northward range expansion for the species. Increased air temperature may also allow northward expansion of red mangroves, thus providing a primary habitat feature for the species outside of the current range. Warming may also affect precipitation patterns and tropical weather events. While increased rainfall could affect river discharges and salinity regimes and hurricanes could damage habitat features, the species has shown to be resilient to these types of stochastic events in the past. However, a change in the frequency or severity of these events could translate to additional effects on the species not previously considered or currently understood. 


\section{DISCUSSION}

Data synthesized in this review have advanced our overall understanding of smalltooth sawfish life history and habitat needs, as well as the threats that continue to affect the remaining population. When considered cumulatively, the information supports optimism for recovery of the smalltooth sawfish in the USA and potentially beyond. Recent studies have shown that the species grows faster and matures earlier than previously thought (Simpfendorfer et al. 2008, Scharer et al. 2012). These changes, in the context of population modeling, indicate that the population is capable of recovering faster than once calculated-provided threats do not increase (Carlson \& Simpfendorfer 2015). Despite these encouraging signs, there has been no significant change in the range limits of the smalltooth sawfish since the ESA listing in 2003, and recovery is still expected to take several decades. This lack of expansion may be related to the parturition site fidelity described by Feldheim et al. (2017) and may require that some adult females seek new parturition sites before population recovery can be achieved. The juvenile population continues to be found predominantly in southwest Florida, particularly within the Charlotte Harbor estuarine system and the federally protected areas of Everglades National Park and the Ten Thousand Islands National Wildlife Refuge. In addition to high use of Florida Bay, adult smalltooth sawfish are found predominantly in the Florida Keys National Marine Sanctuary in both Gulf of Mexico and Atlantic waters. Currently, the population appears to be at least stable, and continuing the long-term fisheries-independent monitoring and research will be a priority for relative abundance assessments and continued biological data collection, and to ensure that the goals of the recovery plan are being met.

A variety of studies have increased our understanding of habitat use, particularly by juveniles, with implications for management and recovery of this species. Habitat use observations reported here help explain the historical importance of Florida to the smalltooth sawfish in the USA and indicate where recovery can be expected in the USA and abroad. The need for conservation and management of existing coastal habitats throughout the species' range is clear (Norton et al. 2012, Carlson et al. 2013), and conservation of specific estuaries in southwest Florida is especially important given their role as nurseries (NMFS 2009b, Simpfendorfer et al. 2010, 2011, Norton et al. 2012, Scharer et al. 2017, Hollensead et al. 2018). However, even within the large- scale nursery areas defined by Norton et al. (2012), Scharer et al. (2017) documented variability in habitat use by location, and thus individual nurseries may require specific management measures. Defining use of and protecting key habitat features at a finer scale within the larger nursery would have implications for management decisions, especially near highly populated areas like Cape Coral, Florida. For example, NMFS resource managers review all federal actions (e.g. projects such as marina construction, dredging, and shoreline stabilization) that have the potential to adversely affect designated juvenile smalltooth sawfish critical habitat, but provide additional scrutiny for projects within identified higher-use areas. This approach has aided in avoiding and minimizing project effects on high-use areas and critical habitat units as a whole, thus benefiting the recovery of the species while balancing human interests. Future efforts should consider randomized fisheries-independent monitoring of small juveniles throughout the known nurseries to identify other high-use areas and throughout Florida to identify if and where other nurseries exist or become established, especially Tampa Bay and the Indian River Lagoon-estuaries into which species expansion is most likely to occur based on historical records, habitat availability, and temperature tolerances of the species (Evermann \& Bean 1898, Poulakis et al. 2011, Scharer et al. 2017).

Large juvenile and adult sawfish use a broader range of habitats over a larger geographic area than small juveniles. This has limited the ability of researchers to catch and study these larger individuals. However, telemetry and satellite tagging efforts have fostered recent gains in our understanding of the ecology of larger size classes. Researchers have tracked movements between the 2 juvenile critical habitat areas (Charlotte Harbor and the Everglades), which supports the genetic evidence indicating that this is a single population with sufficient mixing (Chapman et al. 2011). Tagging efforts have also confirmed that the US population is distinct, as there currently is no evidence of mixing with sawfish collected and tagged in The Bahamas (R. D. Grubbs unpubl. data). Captured mature adults, both males and females, with fresh mating wounds have suggested that mating occurs in the core range from Charlotte Harbor to Florida Bay and the lower Florida Keys (R. D. Grubbs \& G. R. Poulakis unpubl. data). Continued efforts to internally tag sawfish with long-term acoustic tags will aid in identifying any areas where adults aggregate, specific mating grounds, potential parturition sites, seasonal movements, and residency at specific sites. Collectively, 
this future information will be key to determining if and where critical habitat for large juveniles and adults could be designated.

Protected habitats have played an important role in conserving this species. The protection afforded by Everglades National Park, both in terms of the lack of commercial fishing and preservation of nursery habitat, ensured that the population was not locally extinct in US waters before other protections were implemented (Wiley \& Simpfendorfer 2010). The West Side National Park of Andros Island likely serves a similar role in protecting a remnant population of the smalltooth sawfish in The Bahamas. Identifying other potential 'life-boat' populations in other nations and determining whether there is any mixing among these populations requires additional study.

Reducing the threat of injury and mortality from fisheries remains a top priority for recovering the smalltooth sawfish. Prohaska et al. (2018) showed that the species is physiologically resilient and appears capable of surviving capture. Therefore, continuing to educate anglers about the presence of smalltooth sawfish and how to properly release them is essential for recovery. Sawfish handling and release guidelines have been developed for each fishery (commercial and recreational), and wide distribution of these materials is necessary to raise public awareness and promote the conservation and recovery of the species. Through the cooperation of fishing guides and recreational anglers, and through intensive education and outreach efforts, reports of individual catches have increased markedly in recent years, and reports will continue to increase as the population recovers. These publicly derived data will continue to be important in identifying patterns of habitat use and monitoring recovery as they are often the first step in learning about occupied areas (Seitz \& Poulakis 2002, Wiley \& Simpfendorfer 2010, Poulakis \& Grubbs 2019).

Numerous federal, international, and inter-jurisdictional laws, regulations, and policies have the potential to affect the abundance and survival of the smalltooth sawfish. Within the USA, the species is afforded protection under the ESA, and the states of Florida, Louisiana, Alabama, and Texas currently have additional prohibitions. Although the smalltooth sawfish is legally protected in the USA, it is still subject to incidental capture and harm, particularly in the form of rostrum removal. Ending demand for rostra through prosecution and publication of illegal removal and sale is key to minimizing the incentive to kill sawfishes or remove rostra prior to release. While state, federal, and international policies aim to protect saw- fishes and ban or severely restrict commerce in rostra (e.g. the protocol for Specially Protected Areas and Wildlife through the Cartagena Convention, the Convention on International Trade in Endangered Species of Wild Fauna and Flora Appendix I listings, and the Convention on Conservation of Migratory Species Appendix I and II listings), inter-jurisdictional inconsistencies and confusion surrounding applicable regulations hinders enforcement. Regulations affecting US sale and trade of rostra must be clarified and enhanced, such as the uncertainty related to sale of endangered species parts within some state borders, and protection by all coastal states in the historical range is important to ensure recovery of the smalltooth sawfish. The Global Conservation Strategy for Sawfishes (Harrison \& Dulvy 2014) produced by the IUCN Shark Specialist Group reviewed the legal status of smalltooth sawfish throughout the world and lists countries considered as priorities for protection (e.g. The Bahamas, Cuba).

This paper is a comprehensive synthesis of all known data on the smalltooth sawfish in the USA. Although research suggests that the species is physiologically resilient and the population may be stable and possibly increasing at localized scales, the smalltooth sawfish is still at risk due to its depressed population size, prolonged life history strategy, restricted range, and the continuing effects of ongoing threats. We are cautiously optimistic about the potential for recovery of this species, but it is expected to take decades and will require strict enforcement of current regulations to maintain progress and keep the effects of all current and future threats suppressed. Future priority actions should include continued public outreach and education, implementation of relative abundance monitoring programs, and the funding of research projects which address priority concerns. NMFS and the Smalltooth Sawfish Recovery Implementation Team will continue to monitor the population status and the ongoing threats to the population, and will continue to develop priorities to direct research efforts.

Acknowledgements. This review was completed with funding to T.R.W. from NOAA Fisheries under contract WC133F-15-SE-1542. Field activities were carried out under ESA Protected Species Permit 1352 issued to T.R.W., 13330 and 17787 issued to J.K.C., and 1475 and 15802 issued to G.R.P. We thank the members of the Smalltooth Sawfish Status Review Team for providing the justification for the endangered classification, and previous members of the Smalltooth Sawfish Recovery Team for developing the recovery plan. We thank all the staff, volunteers, and interns who have assisted in the field and in the lab. We especially 
thank Colin Simpfendorfer for initiating field studies on US sawfish and being the recovery team leader for many years. We are grateful to Shelley Norton for her years as the NMFS sawfish coordinator and for being a tireless advocate for the recovery team and for sawfish. Portions of this work were presented as part of the 'Biology and Ecology of Sawfishes' symposium at the 2016 annual meeting of the American Elasmobranch Society, which was supported by funding from the Save Our Seas Foundation, Disney Conservation Fund, and the American Elasmobranch Society.

\section{LITERATURE CITED}

Anderson DM, Burkholder JM, Cochlan WP, Glibert PM and others (2008) Harmful algal blooms and eutrophication: examining linkages from selected coastal regions of the United States. Harmful Algae 8:39-53

Bakenhaster MD, Bullard SA, Curran SS, Kritsky DC and others (2018) Parasite component community of smalltooth sawfish off Florida: diversity, conservation concerns, and research applications. Endang Species Res 35: 47-58

Bethea DM, Smith K, Hollensead LD, Carlson JK (2011a) NOAA NMFS smalltooth sawfish monitoring surveyFY10: Relative abundance and essential fish habitat studies for smalltooth sawfish, Pristis pectinata, in Southwest Florida, USA. Panama City Laboratory Contribution 11-02, Southeast Fisheries Science Center, Panama City, FL

Bethea DM, Smith K, Hollensead LD, Carlson JK (2011b) NOAA NMFS smalltooth sawfish monitoring surveyFY11: Relative abundance and essential fish habitat studies for smalltooth sawfish, Pristis pectinata, in Southwest Florida, USA. Panama City Laboratory Contribution 11-11, Southeast Fisheries Science Center, Panama City, FL

Bethea DM, Smith K, Carlson JK (2012) NOAA NMFS smalltooth sawfish monitoring survey-FY12: Relative abundance and essential fish habitat studies for smalltooth sawfish, Pristis pectinata, in Southwest Florida, USA. Panama City Laboratory Contribution 12-08, Southeast Fisheries Science Center, Panama City, FL

Bigelow HB, Schroeder WC (1953) Fishes of the western North Atlantic, Part II. Sawfishes, guitarfishes, skates, rays, and chimaeroids. Mem Sears Found Mar Res, Yale University, New Haven, CT

Boucek RE, Heithaus MR, Santos R, Stevens P, Rehage JS (2017) Can animal habitat use patterns influence their vulnerability to extreme climate events? An estuarine sportfish case study. Glob Change Biol 23:4045-4057

Brand LE, Compton A (2007) Long-term increase in Karenia brevis abundance along the southwest Florida coast. Harmful Algae 6:232-252

Carlson JK, Osborne J (2012) Relative abundance of smalltooth sawfish (Pristis pectinata) based on the Everglades National Park Creel Survey. NOAA Tech Memo NMFSSEFSC-626

Carlson JK, Scott-Denton E (2011) Estimated incidental take of smalltooth sawfish (Pristis pectinata) and an assessment of observer coverage required in the South Atlantic and Gulf of Mexico shrimp trawl fishery. Sustainable Fisheries Division, Panama City Laboratory Contribution 10, SEFSC, Panama City, FL

Carlson JK, Simpfendorfer CA (2015) Recovery potential of smalltooth sawfish, Pristis pectinata, in the United States determined using population viability models. Aquat Conserv 25:187-200

Carlson JK, Osborne J, Schmidt TW (2007) Monitoring the recovery of smalltooth sawfish, Pristis pectinata, using standardized relative indices of abundance. Biol Conserv 136:195-202

Carlson JK, Wiley T, Smith K (2013) Pristis pectinata (errata version published in 2019). The IUCN Red List of Threatened Species 2013: e.T18175A141791261. http://dx.doi. org/10.2305/IUCN.UK.2013-1.RLTS.T18175A141791261 .en (accessed 30 April 2019)

Carlson JK, Gulak SJB, Simpfendorfer CA, Grubbs RD, Romine JG, Burgess GH (2014) Movement patterns and habitat use of smalltooth sawfish, Pristis pectinata, determined using pop-up satellite archival tags. Aquat Conserv 24:104-117

* Chapman DD, Simpfendorfer CA, Wiley TR, Poulakis GR and others (2011) Genetic diversity despite population collapse in a critically endangered marine fish: the smalltooth sawfish (Pristis pectinata). J Hered 102:643-652

* Chin A, Kyne PM, Walker TI, McAuley RB (2010) An integrated risk assessment for climate change: analyzing the vulnerability of sharks and rays on Australia's Great Barrier Reef. Glob Change Biol 16:1936-1953

Compagno LJV (1984) FAO species catalogue. Sharks of the world. An annotated and illustrated catalogue of shark species known to date. II: Carcharhiniformes. FAO Fisheries Synopsis. FAO, Rome

Dulvy NK, Fowler SL, Musick JA, Cavanagh RD and others (2014) Extinction risk and conservation of the world's sharks and rays. elife 3:e00590

*Dulvy NK, Davidson LNK, Kyne PM, Simpfendorfer CA, Harrison LR, Carlson JK, Fordham SV (2016) Ghosts of the coast: global extinction risk and conservation of sawfishes. Aquat Conserv 26:134-153

Evermann BW, Bean BA (1898) Indian River and its fishes. US Comm Fish Fish 22:227-248

*Feldheim KA, Fields AT, Chapman DD, Scharer RM, Poulakis GR (2017) Insights into reproduction and behavior of the smalltooth sawfish Pristis pectinata. Endang Species Res 34:463-471

Field CD (1995) Impact of expected climate change on mangroves. Hydrobiologia 295:75-81

Field IC, Meekan MG, Buckworth RC, Bradshaw CJA (2009) Susceptibility of sharks, rays, and chimaeras to global extinction. Adv Mar Biol 56:275-363

Fields AT, Feldheim KA, Poulakis GR, Chapman DD (2015) Facultative parthenogenesis in a critically endangered wild vertebrate. Curr Biol 25:R446-R447

Guttridge TL, Gulak SJB, Franks BR, Carlson JK and others (2015) Occurrence and habitat use of the critically endangered smalltooth sawfish Pristis pectinata in the Bahamas. J Fish Biol 87:1322-1341

Harrison LR, Dulvy NK (eds) (2014) Sawfish: a global strategy for conservation. IUCN Species Survival Commission, Shark Specialist Group, Vancouver

Heupel MR, Carlson JK, Simpfendorfer CA (2007) Shark nursery areas: concepts, definition, characterization and assumptions. Mar Ecol Prog Ser 337:287-297

*Hollensead LD, Grubbs RD, Carlson JK, Bethea DM (2016) Analysis of fine-scale daily movement patterns of juvenile Pristis pectinata within a nursery habitat. Aquat Conserv 26:492-505

Hollensead LD, Grubbs RD, Carlson JK, Bethea DM (2018) 
Assessing residency time and habitat use of juvenile smalltooth sawfish using acoustic monitoring in a nursery habitat. Endang Species Res 37:119-131

KHu C, Muller-Karger FE, Swarzenski PW (2006) Hurricanes, submarine groundwater discharge, and Florida's red tides. Geophys Res Lett 33:L11601

*Huston CA, Stevens PW, Blaxton RM, Tolley SG, Scharer RM, Tornwall BM, Poulakis GR (2017) Diel movements of juvenile smalltooth sawfish: implications for defining the size of a nursery hotspot. Endang Species Res 34: 311-322

IPCC (Intergovernmental Panel on Climate Change) (2007) Summary for policymakers. In: Solomon S, Qin D, Manning M, Chen Z and others (eds) Climate change 2007: the physical science basis. Contribution of Working Group I to the Fourth Assessment Report of the Intergovernmental Panel on Climate Change. Cambridge University Press, Cambridge, p 1-18

IPCC (2013) Summary for policymakers. In: Stocker TF, Qin D, Plattner GK, Tignor M and others (eds) Climate change 2013: the physical science basis. Contribution of Working Group I to the Fifth Assessment Report of the Intergovernmental Panel on Climate Change. Cambridge University Press, Cambridge, p 1-28

Kyne PM, Carlson J, Smith K (2013) Pristis pristis. The IUCN Red List of Threatened Species 2013: e.T18584848A 18620395 (accessed 13 May 2019)

Lewis M (2008) Response to 'Endangered and threatened species; Initiation of a 5-year review of the endangered U.S. Distinct Population Segment (DPS) of smalltooth sawfish', 73 FR 29482

NMFS (National Marine Fisheries Service) (2000) Status review of smalltooth sawfish (Pristis pectinata). Prepared by the Biological Review Team for the National Marine Fisheries Service, Silver Spring, MD

NMFS (2009a) Recovery plan for smalltooth sawfish (Pristis pectinata). Prepared by the Smalltooth Sawfish Recovery Team for the National Marine Fisheries Service, Silver Spring, MD

NMFS (2009b) Critical habitat for the endangered distinct population segment of smalltooth sawfish. Fed Regist 74: 45353-45378

NMFS (2010) Smalltooth sawfish (Pristis pectinata Latham) 5-year review: summary and evaluation. NMFS, St. Petersburg, FL

Norton SL, Wiley TR, Carlson JK, Frick AL, Poulakis GR, Simpfendorfer CA (2012) Designating critical habitat for juvenile endangered smalltooth sawfish in the United States. Mar Coast Fish 4:473-480

*Papastamatiou YP, Grubbs RD, Imhoff JL, Gulak SJB, Carlson JK, Burgess GH (2015) A subtropical embayment serves as essential habitat for sub-adults and adults of the critically endangered smalltooth sawfish. Glob Ecol Conserv 3:764-775

* Poulakis GR, Grubbs RD (2019) Biology and ecology of sawfishes: global status of research and future outlook. Endang Species Res, doi:10.3354/esr00955

Poulakis GR, Seitz JC (2004) Recent occurrence of the smalltooth sawfish, Pristis pectinata (Elasmobranchiomorphi: Pristidae), in Florida Bay and the Florida Keys, with comments on sawfish ecology. Fla Sci 67:27-35

Poulakis GR, Stevens PW, Timmers AA, Wiley TR, Simpfendorfer CA (2011) Abiotic affinities and spatiotemporal distribution of the endangered smalltooth sawfish, Pristis pectinata, in a south-western Florida nursery. Mar Freshw
Res 62:1165-1177

*Poulakis GR, Stevens PW, Timmers AA, Stafford CJ, Simpfendorfer CA (2013) Movements of juvenile endangered smalltooth sawfish, Pristis pectinata, in an estuarine river system: use of non-main-stem river habitats and lagged responses to freshwater inflow-related changes. Environ Biol Fishes 96:763-778

Poulakis GR, Stevens PW, Timmers AA, Stafford CJ and others (2016) Long-term site fidelity of endangered smalltooth sawfish (Pristis pectinata) from different mothers. Fish Bull 114:461-475

*Poulakis GR, Urakawa H, Stevens PW, DeAngelo JA and others (2017) Sympatric elasmobranchs and fecal samples provide insight into the trophic ecology of the smalltooth sawfish. Endang Species Res 32:491-506

*Pohaska BK, Bethea DM, Poulakis GR, Scharer RM, Knotek R, Carlson JK, Grubbs RD (2018) Physiological stress in the smalltooth sawfish: effects of ontogeny, capture method, and habitat quality. Endang Species Res 36: 121-135

* Scharer RM, Patterson WF III, Carlson JK, Poulakis GR (2012) Age and growth of endangered smalltooth sawfish (Pristis pectinata) verified with LA-ICP-MS analysis of vertebrae. PLOS ONE 7:e47850

* Scharer RM, Stevens PW, Shea CP, Poulakis GR (2017) All nurseries are not created equal: large-scale habitat use patterns in two smalltooth sawfish nurseries. Endang Species Res 34:473-492

Seitz JC, Poulakis GR (2002) Recent occurrence of sawfishes (Elasmobranchiomorphi: Pristidae) along the southwest coast of Florida (USA). Fla Sci 65:256-266

Seitz JC, Poulakis GR (2006) Anthropogenic effects on the smalltooth sawfish (Pristis pectinata) in the United States. Mar Pollut Bull 52:1533-1540

Semeniuk V (1994) Predicting the effect of sea-level rise on mangroves in northwestern Australia. J Coast Res 10:1050-1076

Simpfendorfer CA (2000) Predicting recovery rates for endangered western Atlantic sawfishes using demographic analysis. Environ Biol Fishes 58:371-377

Simpfendorfer CA (2002) Smalltooth sawfish: the USA's first endangered elasmobranch? Endang Species Update 19: 45-49

Simpfendorfer CA (2005) Threatened fishes of the world: Pristis pectinata Latham, 1794 (Pristidae). Environ Biol Fishes 73:20

Simpfendorfer C (2013) Pristis zijsron (errata version published in 2019). The IUCN Red List of Threatened Species 2013: e.T39393A141792003. http://dx.doi.org/ 10.2035/IUCN.UK.2013-1.RLTS.T39393A141792003.en (accessed 23 April 2019)

Simpfendorfer CA, Poulakis GR, O'Donnell PM, Wiley TR (2008) Growth rates of juvenile smalltooth sawfish Pristis pectinata Latham in the western Atlantic. J Fish Biol 72: 711-723

Simpfendorfer CA, Wiley TR, Yeiser BG (2010) Improving conservation planning for an endangered sawfish using data from acoustic telemetry. Biol Conserv 143:1460-1469

Simpfendorfer CA, Yeiser BG, Wiley TR, Poulakis GR, Stevens PW, Heupel MR (2011) Environmental influences on the spatial ecology of juvenile smalltooth sawfish (Pristis pectinata): results from acoustic monitoring. PLOS ONE 6:e16918

Stevens PW, Blewett DA, Casey JP (2006) Short-term effects of a low dissolved oxygen event on estuarine fish assem- 
blages following the passage of Hurricane Charley. Estuaries Coasts 29:997-1003

Thorburn D, Morgan D, Gill H (2004) Biology and cultural significance of the freshwater sawfish (Pristis microdon) in the Fitzroy River Kimberley, Western Australia. Freshwater Fish Group at the Centre for Fish \& Fisheries Research, Murdoch University, Perth

Vargo GA (2009) A brief summary of the physiology and ecology of Karenia brevis Davis (G. Hansen and Moestrup comb. nov.) red tides on the West Florida Shelf and of hypotheses posed for their initiation, growth, maintenance, and termination. Harmful Algae 8:573-584

Editorial responsibility: Brendan Godley,

University of Exeter, Cornwall Campus, UK
Waters JD, Coelho R, Fernandez-Carvalho J, Timmers AA and others (2014) Use of encounter data to model spatiotemporal distribution patterns of endangered smalltooth sawfish, Pristis pectinata, in the western Atlantic. Aquat Conserv 24:760-776

White S, Henningsen A (2017) North American regional studbook for Pristidae species. Ripley Entertainment, Myrtle Beach, SC

Wiley TR, Simpfendorfer CA (2010) Using public encounter data to direct recovery efforts for the endangered smalltooth sawfish Pristis pectinata. Endang Species Res 12: 179-191

Submitted: September 26, 2016; Accepted: February 25, 2019 Proofs received from author(s): April 24, 2019 